\title{
Assessment of established cases of chronic simple glaucoma
}

\author{
R. F. FISHER*, R. G. GARPENTER, AND G. WHEELER \\ Institute of Ophthalmology, University of London
}

Since tonography was first introduced by Grant (1950), patients with chronic simple glaucoma have repeatedly been shown to have a marked reduction in outflow facility (Kronfeld, I96I). Impaired outflow has also been correlated with changes in the structure and patency of the trabecular meshwork (Teng, Paton, and Katzin, 1955; Yamashita, Becker, and Cibis, 1960). This confirmed the view that impaired outflow facility, together with cupping of the disc and loss of the field, were constant characteristics of the glaucomatous eye (Becker and Shaffer, 196r). The present study was therefore undertaken in proven cases of chronic simple glaucoma, as indicated by cupping of the disc and loss of the field, firstly to discover if impaired outflow facility were a better measure of the degree of glaucoma than raised intraocular pressure and, secondly, to see if it were possible to predict the loss of field from the impaired outflow facility.

\section{Material and methods}

In the course of 18 months, 400 patients with proven open-angle chronic simple glaucoma presented for treatment and from these patients 33 (fifty eyes) were chosen for this survey. Two factors account for this low rate of selection:

(I) Only patients who had received no previous treatment were included;

(2) Of these patients only a few fulfilled the stringent criteria for field testing (Fisher, I968).

To obtain a full range of cases a few apparently normal eyes of patients with undoubted chronic simple glaucoma in the other eye were included. All eyes were subjected to a general ophthalmological examination, which included gonioscopy.

\section{FIELD ESTIMATION}

The method of selection and examination of the visual fields has been described previously (Fisher, 1968). In this study all quadrants of the field were examined separately in a Goldmann perimeter, with a target of $4 \mathrm{~mm}^{2}$ and of brightness 45 apostilbs. This target was used since the diagnosis was not in question and only definite and permanent field defects were ascertained. Furthermore, a target of this size and luminosity gives an average field, extending about $45^{\circ}$ in the nasal quadrant, and nose and brow obstruction is usually absent (Fisher, 1967). The centripetal and centrifugal fields were repeated on two separate occasions, and if discrepancies greater than $5^{\circ}$ per quadrant were found the patient was excluded from the study. 
For the purpose of computer analysis, the loss of field of each patient was corrected for the norma senile decrease in the size of the field. This correction was made as follows: after the size of the fiel(혀 in each quadrant had been measured, the average size of the field per quadrant in normal subjects. of the same age was obtained from published tables (Fisher, I968). The difference between these two values was taken as the corrected loss of field.

TONOMETRY AND TONOGRAPHY

Intraocular pressures were recorded by applanation tonometry, using the Haag-Streit 900 slit lamp and tonography was performed with the Schwarzer electronic tonometer with recorder. Eack patient was examined on three occasions by tonometry and tonography. The time of examination $\vec{P}$ was arranged at three successive visits for about 9-10 a.m., then $1.30-2$ p.m., and finally $4.30-5$ p.m $\overrightarrow{\vec{\omega}}$ Tonography results were obtained by the rigidity-corrected graphic method of Moses and Beckew (1958).

ESTIMATION OF CUPPING OF THE DISC

The estimation of the cupping of the disc, which was performed by one of us (R.F.F.) before and other investigations, was graded into six groups: normal, doubtful, and four grades of glaucomatoug cupping of increasing severity, as suggested by Becker and Shaffer (196r).

SIZE OF THE PUPIL

This was an average value of eight estimations during the two field tests taken 5 minutes after the eye had been light-adapted to a standard background illumination of 45 apostilbs.

\section{ANALYSIS OF RESULTS}

The data were transferred to punched cards for computer analysis by one of us (R.G.C.). A pre liminary analysis was carried out with a BMD computer programme (Dixon, ig66). The correlation of each pair of variables was computed and most of the relationships plotted. Finally a multiple regression analysis, using the method of Rushton (1951), was undertaken to ascertain the best pre dictors of field-loss in each of the four quadrants.

\section{Results}

One of the most important observations in this study is the close relationship between thê state of the disc and the size of the field. The correlation between these variables is so great that it is possible to relate them in three of the four field quadrants by linear or quadratic equations. This means that the recording of individual results in the form of

Table becomes unnecessary and this has therefore been omitted.
Fig. I shows these relationships. It will be seen that the upper nasal field shows a rapio linear or proportionate loss and this can be represented by the equation:

(a) $\mathrm{F}=45.9-8.4 \mathrm{D}$, where $\mathrm{F}=$ size of field in degrees

$\mathrm{D}=$ numerical coefficient of cupping of the disc.

The lower nasal and upper temporal quadrants show a more gradual loss, representedo by the quadratic equations :

(b) $\mathrm{F}=47-\mathrm{I} \cdot 6 \mathrm{D}^{2}$

(c) $\mathrm{F}=46+4 \cdot 7 \mathrm{D}-2 \cdot 5 \mathrm{D}^{2}$. 


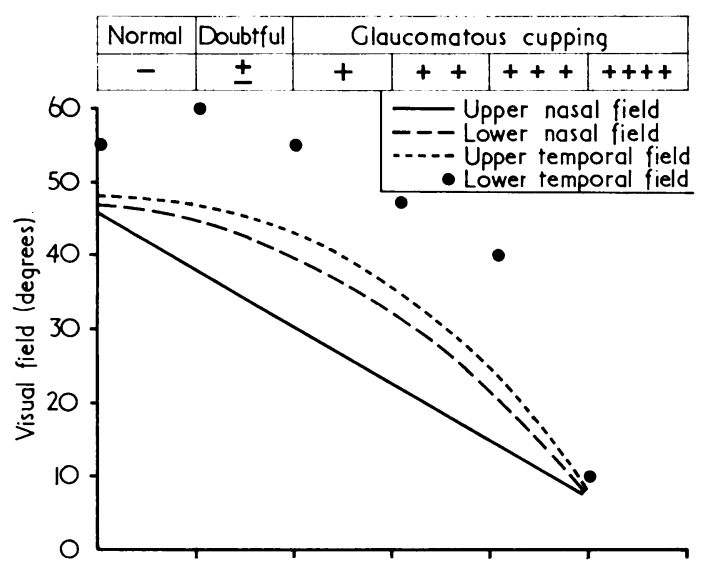

FIG. I Relationship between state of disc and size of field for each quadrant of the visual field

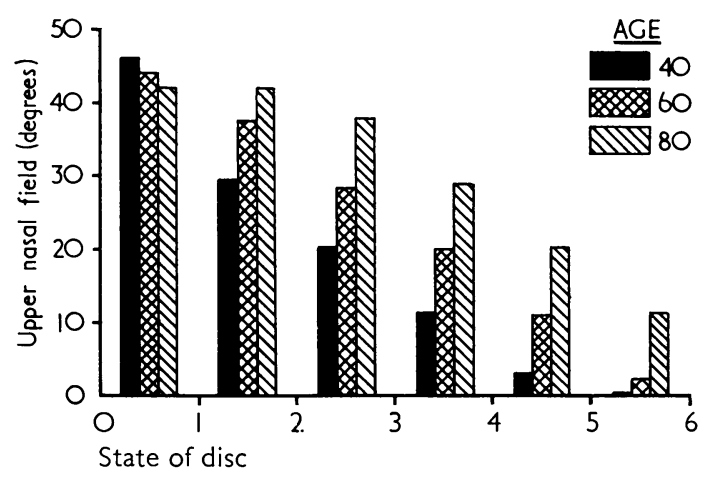

FIG. 2 Significance of glaucomatous cupping in relation to upper nasal loss of the visual field and age

Note The normal values are taken from a normal group of 105 eyes (Fisher, 1968)

The lower temporal field loss cannot be completely described by a quadratic curve since it occurs too late in the disease. It is therefore shown as a series of points corresponding to the average loss for each state of the disc.

All the other observations show much less significant relationships with each other and can therefore be expressed only by a single correlation coefficient. Table I (see p. 220) shows these correlations between age, pupil, field quadrants, pressure range, facility outflow, facility range, and state of the disc.

As mentioned previously, the correlation between the state of the disc and the size of the field is greater than that between any other pair of variables, apart from the correlations between field quadrants. It is disappointing to find that the complex objective assessment of outflow facility is less closely correlated with the reduced size of the field than the simple subjective and inexact assessment of the cupping of the disc. Furthermore, inspection of the plots of the relationships between size of field and average pressure, and of size of field and average outflow facility, does not suggest that these lower correlations are due to the relationships' being non-linear. These lower correlations indicate, therefore, that the size of the field is better assessed by inspection of the disc than by measurement of either pressure or outflow facility.

\section{Discussion}

A well-established case of chronic simple glaucoma has the characteristic clinical features of excavation of the optic nerve head, raised intraocular pressure, and typical field defects. 
A common defect is peripheral loss in the upper nasal field. Nearly a century ago, Schmidt (1877) suggested that selective impairment of circulation in the lower temporal portion of the retina was the cause. Recently it has been found that after the age of 60 , even in normal subjects, loss occurs in the upper nasal field quadrant (Fisher, I968). Even when, as in the present study, this senile loss is taken into account, there is still, with early cupping of the disc, a selective loss of field in this quadrant.

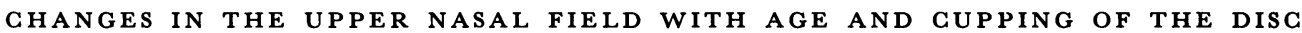

The influence of age upon the extent of loss of field, resulting from a given degree of cupping of the disc, was found in the present data to be related by the equation:

$\mathrm{F}=2 \mathrm{I} \cdot 2-8 \cdot 9 \mathrm{D}+0 \cdot 42 \mathrm{~A}$

where $\mathrm{A}=$ age of patient in years,

$\mathrm{D}=$ numerical coefficient of disc cupping,

$\mathrm{F}=$ size of field in degrees.

The last term of this equation, representing the age of the patient, is additive. This implies that the loss of the field for a given degree of glaucomatous cupping is less pronounced the greater the age of the patient. Although appearing to conflict with the previous finding, that the loss of field occurs as an ageing process even in normal subjects, it merely shows that glaucomatous cupping of the disc in this age group causes a smaller amount of loss of field.

This is shown graphically in Fig. 2 (see p. 219) for the selected ages of 40,6o, and 80 years. A moderate degree of disc cupping $(++)$ at the age of 40 years causes a field loss of 75 per cent., while the same degree of cupping for the ages of 60 and 80 years causes field losses of 45 per cent. and I 5 per cent. respectively. This equation, therefore, gives a precise indication of the seriousness of the cupping of the disc in young patients. Conversely, the elderly patient, with a markedly cupped disc, may only have a slight or moderate loss in the upper nasal field.

GORRELATION BETWEEN STATE OF THE DISG AND SIZE OF THE FIELD

The analysis described in the Appendix has confirmed that in the glaucomatous eye:

(a) Field defects and cupping of the disc are the most stable characteristics.

(b) There is a selective and early progressive impairment of the upper nasal field.

(c) There is later and slower loss of field in the upper temporal and lower nasal fields.

(d) There is late but eventually rapid impairment of the lower temporal field.

(e) Subsidiary measurements, such as pressure and outflow facility, do not have any importance in modifying an estimation of the loss of field from the appearance of the disc.

Thus the view of Graham and Hollows (1966) is confirmed, that, despite the difficulty of grading changes at the disc, ophthalmoscopy is the best method of detecting positive cases of simple glaucoma.

CORRELATION BETWEEN LOSS OF FIELD, INTRAOGULAR PRESSURE, AND OUTFLOW FACILITY

Table I shows that overt cases of chronic simple glaucoma have a reduced size of the visual field which tends to correlate more closely with mean raised intraocular pressure than with mean reduced outflow facility. The upper nasal field very significantly correlates with both values (Pressure $r=-0.50 \mathrm{I}$; outflow facility $r=0.45^{2}$; in both cases $0.00 \mathrm{I}>\mathrm{P}$ ). 
These correlations are shown graphically in Figs 3 and 4. Table I also shows that mean outflow facility correlates very significantly with intraocular pressure $(r=-0.588 ; \bar{\Xi}$ $\mathrm{P}<\mathrm{0} \cdot 00 \mathrm{I})$. This correlation illustrates the well-established dependence of raised pressure upon low outflow facility.

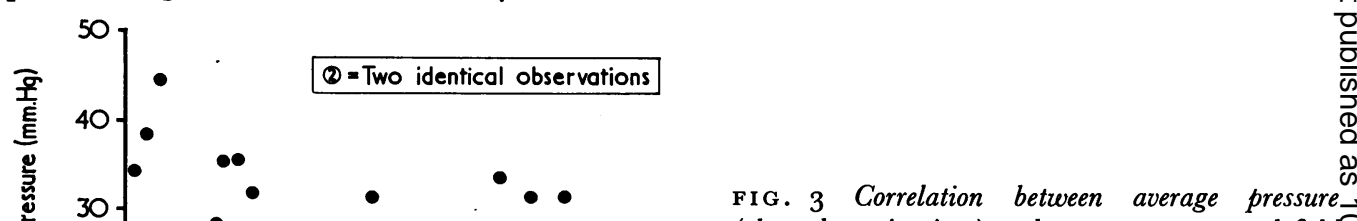
(three determinations) and average upper nasal field. (two estimations)
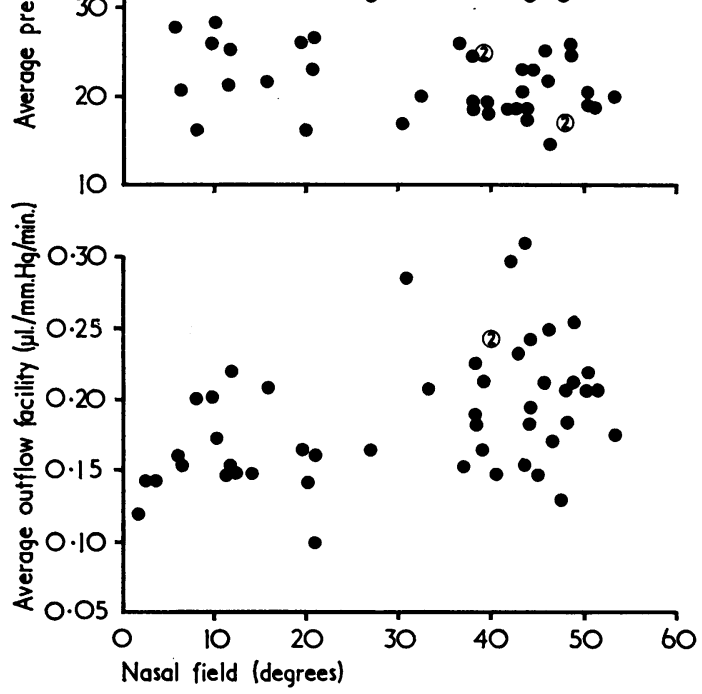

FIG. 4 Correlation between average outflow facility (three determinations) and average upper $\overrightarrow{0}$ nasal field (two estimations)

The value of tonography compared with pressure estimations in assessing the glauco- $\overrightarrow{\overrightarrow{0}}$ matous state must now be considered. This consideration involves the definition of the "degree of glaucoma" as a decrease in the size of the field, and, secondly, using the average values of three outflow facility measurements and three intraocular pressure readings, recorded together on separate occasions throughout the day for correlating in turn with the size of the field. When this was done, the complex technique of tonography was of less value in assessing glaucoma than the simple measurement of the intraocular pressure. Furthermore, the partial correlations between size of field and average outflow facility, when pressure is held constant, are insignificant for each field (Table VI, see p. 228). Thuso tonography provides no information about the "degree of glaucoma" not given by tono- $\rightarrow$ metry. This view so contradicts much of current thought in regard to the value of tonography as an estimate of the glaucomatous state that it must be discussed in detail. These $\tilde{O}^{-}$ findings could be due to $(a)$ imperfections of tonographic technique in the present study; or to an incorrect view regarding $(b)$ the calculation of outflow facility; or $(c)$ the constancy N of outflow facility values compared with pressure readings.

(a) Tonographic technique

It could well be argued that poor tonographic technique resulted in the low correlation of outflow facility with glaucomatous field size. Since, however, tonography was repeated ${ }_{0}^{-}$ three times in every eye, it is easy to compare the variations obtained with those found by other workers. Gloster (1966) suggested that the variation in tonography was about苂 20 per cent. above or below the mean value. In this series the mean value is $0.19 \mu \mathrm{l} . / \mathrm{mm} . \underbrace{\circ}$ 
$\mathrm{Hg} / \mathrm{min}$., the mean range $0.05 \mu \mathrm{l}$, and the average variation for a single reading $26 \mathrm{per}$ cent. Becker and Shaffer (I96I) gave the standard deviation for a normal population as $\pm 0.05 \mu \mathrm{l}$. In this series, where outflow facility values are reduced, the standard deviation was plus or minus $0.036 \mu \mathrm{l}$. The variations found in this study do not therefore differ from those found by others, and, in addition, all the tonographies were performed by one person (C.W.) using the same instrument.

\section{(b) Outflow facility measurement}

Tonography was introduced to give a stable and reproducible numerical coefficient for the rate of flow of aqueous per mm. $\mathrm{Hg}$ pressure, through the outflow channels of the eye. Some of the basic assumptions have been critically reviewed on many occasions, for example by Kronfeld (I96I). One assumption, namely the uniformity of blood flow through the choroidal vasculature, has been shown to be reasonably constant by radioactive plasma or labelled red blood cell studies. It is little appreciated, however, that slight variations in choroidal thickness, quite outside the accuracy of present methods of estimating the blood flow, can cause profound variations in the intraocular volume. For example, if the choroid increased by only $2 \mu$-the thickness of a single red blood cellduring a tonographic estimation of 4 minutes' duration, the measurement of outflow facility would be underestimated by about 75 per cent. in an eye with moderately advanced glaucoma.

A further assumption, that outflow facility is independent of intraocular pressure, has been used to calculate changes in the properties of the trabecular meshwork (McEwen, I958). These calculations presupposed the constant calibre of the outflow channels but Clausen and Harris ( 1965 ) have shown that the outflow facility in the cat can be altered by a raised intraocular pressure. It was found in this study that tonography performed at different times during the day was more variable than pressure, the individual variation being 27 per cent. for tonography and 16 per cent. for pressure. Variations in tonographic values in normal and glaucomatous eyes throughout the day have also been reported previously (Newell and Krill, I965; Berry, Drance, and Wiggins, r 967).

Indeed, when average values for outflow facility, together with average measurements of intraocular pressure, were compared with the size of the field, the degree of glaucoma was less closely correlated with outflow facility (Table I). One is forced, therefore, to conclude that, if tonographic assumptions are correct even in the glaucomatous eye, outflow channels still have large diurnal changes in resistance. These changes in resistance, like variations in pressure, adversely affect the correlation between outflow facility and decreasing size of field.

\section{(c) Constancy of outflow facility and pressure}

If it could be shown that tonographic and pressure variations correlated to a similar degree with autonomic ocular tonus, then changes in outflow facility, like those in pressure, could be attributed not to defects in technique or methods of calculation but to true alterations in outflow resistance. Much work has been done on the relationship between nervous activity and intraocular pressure and, to a lesser extent, on outflow facility; but the precise importance of the ocular autonomic nerve supply is still a matter of speculation (Schmerl and Steinberg, I949; Gloster and Greaves, 1957). Fortunately, an indication of the balance between the parasympathetic and sympathetic activity of the eye may be deduced from the size of the pupil. 
Do changes in outflow vary significantly with the size of the pupil? If they do not, then it is a stable characteristic of the glaucomatous eye, like cupping of the disc and loss of field. It should be noted, from Table I, that the size of field in this glaucomatous population and the state of the disc have non-significant correlations with pupillary size. $\stackrel{\vec{\nexists}}{\stackrel{*}{9}}$ If outflow facility variation does indeed correlate with pupillary size, it is, like raised pressure, only another labile characteristic of the glaucomatous state.

In the present study the size of the pupil was shown to have a significant negative correla- $\stackrel{\mathbb{Q}}{\stackrel{2}{ }}$ tion with both pressure (P less than o.0I: Table I) and with outflow facility (P less than $0 \cdot 05$ : Figs 5 and 6$)$. All other variables, apart from age, showed no significant correlation $\vec{\circ}$ with pupillary size. It is well established that the pupil decreases in size with age (Birren, $\vec{\omega}$ Casperson, and Botwinick, 1950) and a survey of normal cases under the same conditions of illumination showed an even more significant correlation with age $(r=0.70 \mathrm{I})$ over an extended age range ( 15 to $8 \mathrm{I}$ years) (Fisher, 1968 ). However, even if the significant effect of age in pupillary size is allowed for, by a calculation of the partial coefficients of pressure variation and outflow facility variation with pupillary size, the latter values still $\underset{\sim}{\exists}$ remain significant (pressure variation $r=-0.369$; outflow facility variation $r=:=0$ $-0.318)$.

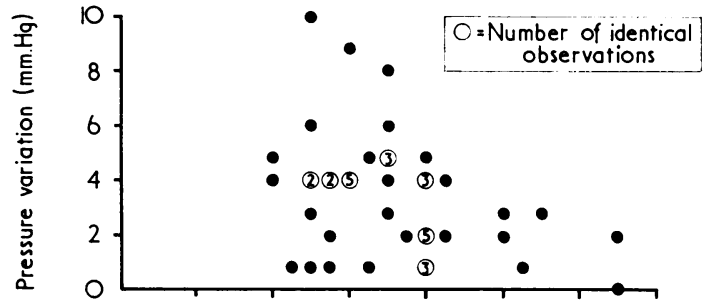

FIG. 5 Correlation between each subject's variation in pressure (three determinations) and mean pupillary size (eight determinations)

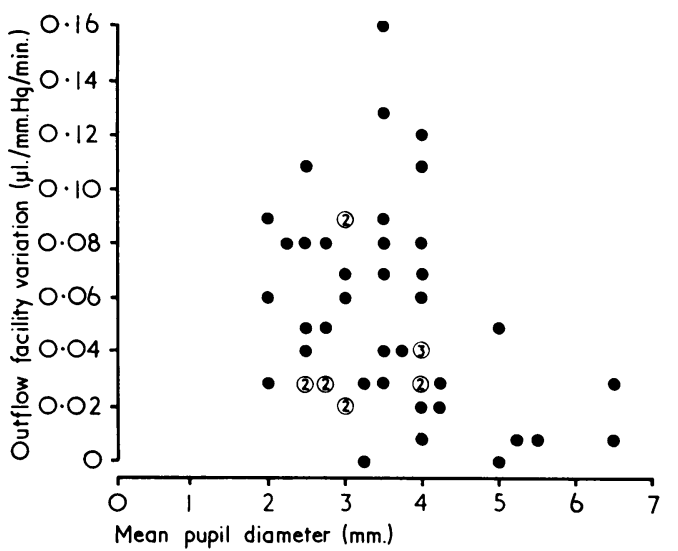

FIG. 6 Correlation between each subject's variations in outflow facility (three determinations) and mean pupillary size (eight determinations)

Törnqvist (1967) had shown that in the primate eye the parasympathetic probably plays the predominant role in miosis and accommodation, so that the smaller the pupil the greater the parasympathetic tonus. If this is so, increased parasympathetic tonus would $\stackrel{D}{D}$ automatically lead to the possibility of greater change if it were inhibited. This, in turn, $\stackrel{\infty}{+}$ would be reflected in pupillary miosis, correlating with large pressure and outflow varia- $\frac{0}{0}$ tions. For example, from Figs 5 and 6 , with a pupillary size of $2 \mathrm{~mm}$., outflow facility $\underset{\mathbb{D}}{\mathrm{D}}$ variation is $0.08 \mu \mathrm{l}$. and pressure variation is $5.0 \mathrm{~mm}$. $\mathrm{Hg}$, while with a pupillary size of $\frac{\Omega}{\mathbb{D}}$ $5 \mathrm{~mm}$., outflow facility varies only by $0.035 \mu \mathrm{l}$. and pressure only by $\mathrm{I} \cdot 5 \mathrm{~mm}$. $\mathrm{Hg}$. 
Duke-Elder (1957) expressed the view that the secret of this disease could not be entirely expressed in terms of mathematical formulae, and it would seem that the careful measurement of outflow facility in this study supports this view. Until we can evolve better methods of studying the degree of cupping of the optic nerve head, and forecasting its resistance to raised intraocular pressure, further refinements of tonographic techniques are unlikely to yield more useful information in the management of simple glaucoma.

\section{Summary}

A statistical correlation between the various characteristics of fifty glaucomatous eyes has shown that simple subjective assessment of cupping of the disc correlated more closely with the decrease in the size of the visual field than with either intraocular pressure or outflow facility. Furthermore, when the averages of pressure and outflow facility were separately correlated with mean quadratic size of field, average pressure readings correlated more closely than average outflow facility values. Since variations in pressure in individual subjects and in outflow facility also correlated significantly with the size of the pupil, it was concluded that reduced outflow facility was no more a stable property of the glaucomatous eye than raised intraocular pressure.

We are indebted to Mr. Redmond Smith for the facilities to examine patients referred to the Glaucoma Clinics of Moorfields Eye Hospital, and to the Imperial College computing centre and the Cambridge mathematical laboratory for the use of their computers for this analysis.

\section{References}

BEGKER, B., and SHAFFER, R. N. (I96I) “Diagnosis and Therapy of the Glaucomas”, p. I I6,

Mosby, St. Louis

Berry, v., Drance, s. M., and Wiggins, R. L. (I967) Canad. J. Ophthal., 2, 4 I

birren, J. e., CASPERSon, R. C., and botwinick, J. (i950) J. Geront., 5, 2 i 6

Clausen, D. F., and HARRis, J. E. (1965) Exp. Eye Res., 4, 67

Dixon, w. J. (ig66) “B.M.D. Biomedical Computer Programmes”, pp. 49-59. University of

California

DUKE-Elder, s. (1957) Trans. ophthal. Soc. U.K., 77, 205

FISHER, R. F. (1967) Vision Res., 7, 671

(1968) Docum. ophthal. (Den Haag), 24, $4^{1}$

Gloster, J. (ig66) In "Glaucoma: Proceedings of a Symposium, Royal College of Surgeons of

England, 1965”, ed. L. B. Hunt, p. 66. Livingstone, Edinburgh

- and Greaves, D. P. (I957) Brit. J. Ophthal., 4r, $5^{1} 3$

GRAham, P. A., and hollows, F. C. (I966) In "Glaucoma: Proceedings of a Symposium, Royal

College of Surgeons of England, 1965", ed. L. B. Hunt, p. 103. Livingstone, Edinburgh

GRANT, w. M. (I950) Arch. Ophthal. (Chicago), 44, 204

kronfield, p. c. (ig6I) "Symposium: Tonography", Trans. Amer. Acad. Ophthal. Otolaryng., 65, I33

McEWen, w. E. (i 958) A.M.A. Arch. Ophthal., 6o, 290

moses, R. A., and Becker, B. (1958) Amer. J. Ophthal., 45, 196

NEWEll, F. W., and KRILl, A. E. (1965) Ibid., 59, 840

RUSHTON, s. (I95I) J. roy. stat. Soc. B, r3, $9^{2}$

SChmerl, e., and Steinberg, B. (1949) Amer. J. Ophthal., 32, 947

schмidт, н. (I877) In "Handbuch der gesammten Augenheilkunde", ed. A. Graefe and T.

Saemisch, vol. 5, p. 6 . Engelmann, Leipzig

TENG, c. C., paton, R. т., and kAtzin, H. м. (1955) Amer. J. Ophthal., 40, 6 I9

TÖRNQVist, G. ( 1967 ) Invest. Ophthal., 6, 6 I 2

yamashita, т., Becker, B., and cibis, P. (i96o) Amer. J. Ophthal., 50, 407 


\title{
Appendix
}

\author{
*R. G. CARPENTER
}

\section{The multiple regression analysis}

We looked for the best predictor of size of field among the following variables:

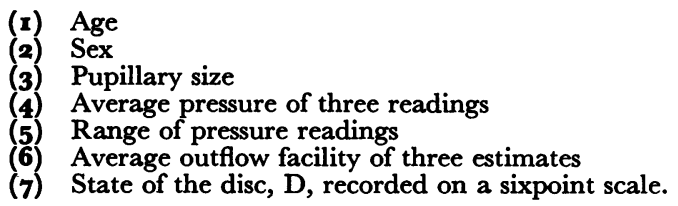

Scatter diagrams showing the relationships between the size of the field and the first six variables did not suggest that they were non-linear, but the relationships between the size of the field and state of the disc were obviously not linear for some fields. The mean loss of field corresponding to each of $\vec{V}$ the five abnormal states of the disc can be completely represented by the regression of size of the 윽 field on $\mathrm{D}, \mathrm{D}^{2}$, and three other constants. The relationship between the size of the field with each of these terms was considered.

Table II shows the partial correlations between the size of the field and each of the other variables after removing the contributory state of the disc, i.e., these correlations are the average correlations between the size of the field and age, pupillary size, pressure, etc., within a given state of the disc.

Table II Partial correlations after taking account of correlation, size of field, and state of disc

\begin{tabular}{lrrrrr}
\hline Variable & $\begin{array}{l}\text { Upper } \\
\text { nasal }\end{array}$ & $\begin{array}{l}\text { Lower } \\
\text { nasal }\end{array}$ & $\begin{array}{l}\text { Upper } \\
\text { temporal }\end{array}$ & $\begin{array}{l}\text { Lower } \\
\text { temporal }\end{array}$ \\
\cline { 3 - 6 } Age (yrs) & & $0.438 \ddagger$ & 0.205 & 0.015 & -0.007 \\
Pupillary size & $-0.311 \dagger$ & -0.212 & -0.243 & -0.200 \\
Pressure & -0.115 & -0.143 & -0.110 & -0.087 \\
Pressure range & 0.007 & -0.224 & -0.130 & -0.149 \\
Outflow & 0.160 & 0.166 & -0.187 & -0.035 \\
Outflow range & 0.164 & $0.320 \dagger$ & 0.189 & 0.283 \\
\hline
\end{tabular}

Significance levels

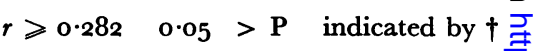
$r \geqslant 0.365$ o.01 $>\mathrm{P}$ indicated by $\ddagger$. $r \geqslant 0.455 \quad 0.001>P$ indicated by $* \frac{0}{0}$

The probability of observing a correla- $\frac{0}{3}$ tion with module larger than $0 \cdot 438$ is $<0 \cdot 0016$. Hence the probability of $\delta$ observing one such correlation in 24 is $<0 \cdot 039$.

Table III (opposite) shows that all these correlations are small and that only four are statistically significant-three at the 5 per cent. level and one at the I per cent. level. Among 24 correlations these might easily exceed the 5 per cent. level by chance, but the probability of a single partial $\cap$ correlation exceeding 0.438 by chance is less than 0.16 per cent., and so the chance of observing one $\omega$ correlation as large as this among 24 is less than 4 per cent. Thus it is concluded that the partial correlation between age and loss of the upper nasal field is statistically significant.

Table III shows the analysis of variance when the size of the upper nasal field was regressed on $\stackrel{?}{?}$ the state of the disc after the first six variables. This shows that the state of the disc provides informa- $\frac{T}{0}$ tion about the size of the field that is not contained in any of the other observations. It also shows $\frac{0}{\mathbb{D}}$ that, for the upper nasal field, the relationship between the state of the disc and the size of the field is fully described by a straight line. 
Table III Analysis of effect of state of disc after six other variables on size of upper nasal field corrected for age

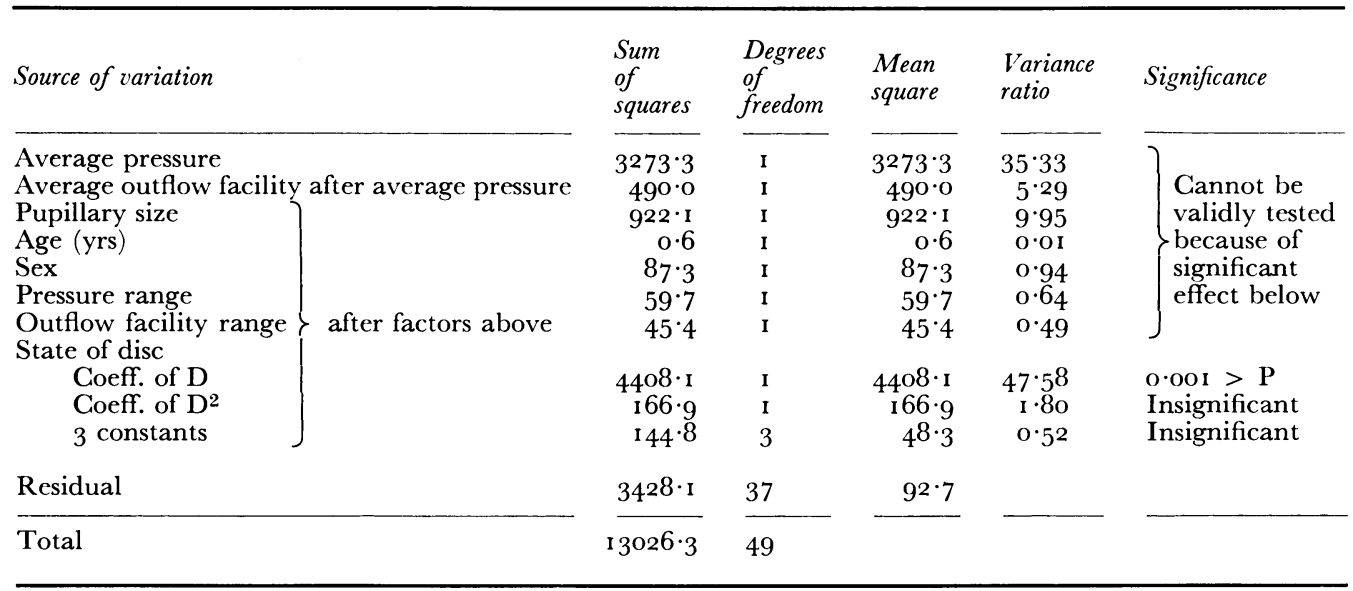

Table IV presents the analysis of variance when the size of the upper nasal field is regressed first on the state of the disc, treated as a linear variable, and then on each of the other variables in succession. Of these, besides the state of the disc, age is the only other significant variable in the regression.

Table IV Analysis of effect of six variables after state of disc on size of upper nasal field, corrected for age

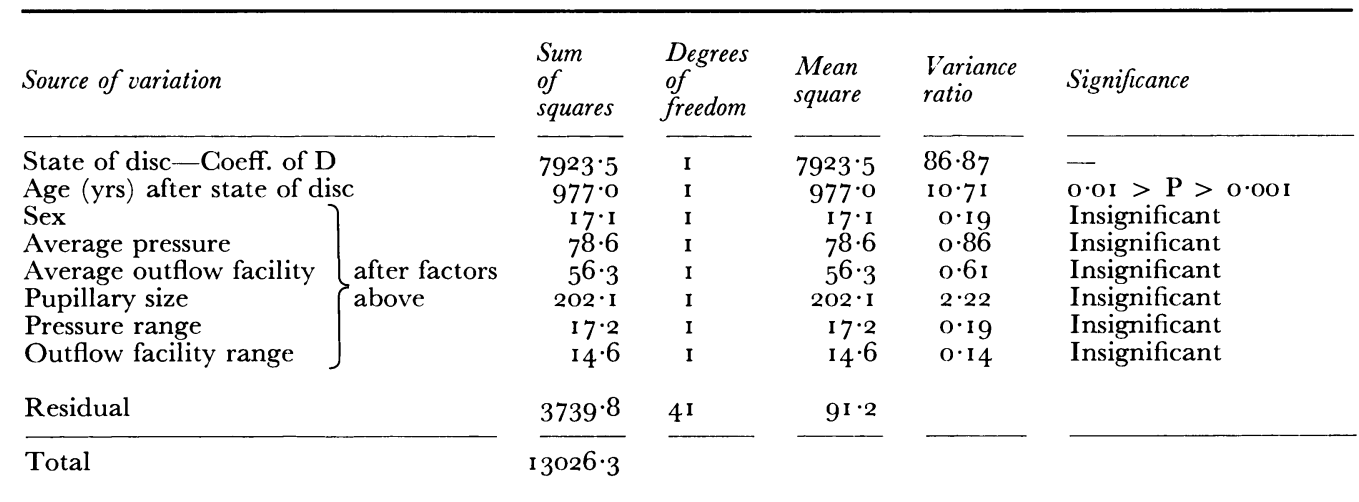

Similar multiple regression analyses were carried out for each of the other fields. For the lower nasal field both $\mathrm{D}$ and $\mathrm{D}^{2}$ were significant, but neither the range of outflow facility nor any of the other variables is significant after regressing on $\mathrm{D}$ and $\mathrm{D}^{2}$. The size of the upper temporal field is highly correlated with the state of the disc, and the relationship can be fully described by the quadratic term $D^{2}$. In addition, average outflow facility is also just significant for upper temporal field, the partial correlation being $-0 \cdot 295 ; 0 \cdot 05>\mathrm{P}>0 \cdot 0 \mathrm{I}$.

The relationship between the lower temporal size of the field and the state of the disc can be fully described only by fitting a constant for each state of the disc. After fitting these constants, no other variable by itself is significant, but a constellation of four variables was found which together were significant at the 5 per cent. level. These four variables were sex, average pressure, range of pressure, and range of outflow facility. There was no obvious explanation why a linear combination of these four variables should predict the size of the lower temporal field. 
Thus, for all four fields, after taking account of the highly significant effect of the state of the disc, only marginally significant relationships were found, apart from a highly significant effect of age on size of the upper nasal field. These marginally significant relationships are probably due to the ․ large number of relationships that have been examined, and we regard them as fortuitous. The $\overrightarrow{\vec{F}}$ regression equations found in these analyses are given in Table V.

Table $\mathbf{V}$ Coefficients of significant variables, with standard errors, for predicting size of field in degrees

Residual standard deviation of size of field also shown in degrees

\begin{tabular}{|c|c|c|c|c|}
\hline Field & Coefficient of & & Constant & Residual SD \\
\hline Upper nasal ${ }^{1}$ & $\begin{array}{l}\mathrm{D} \\
-8 \cdot 28 \pm 0 \cdot 89\end{array}$ & $\begin{array}{l}\text { Age (yrs) } \\
0.582 \pm 0.179\end{array}$ & $14 \cdot 8$ & $9 \cdot 6$ \\
\hline Lower nasal2 & $\begin{array}{l}\text { D } \\
4 \cdot 70 \pm 2 \cdot 08\end{array}$ & $\begin{array}{l}\mathrm{D}^{2} \\
-2.53 \pm 0.44\end{array}$ & $46 \cdot 0$ & $6 \cdot 9$ \\
\hline Upper temporal ${ }^{2}$ & $\begin{array}{l}\mathrm{D}^{2} \\
\mathrm{I} \cdot 57 \pm 0 \cdot 17\end{array}$ & & $41 \cdot 7$ & $8 \cdot 9$ \\
\hline Lower temporal ${ }^{2}$ & $\begin{array}{l}\text { Constants correspo } \\
\text { o } \quad+-\frac{+}{6 I \cdot I} \quad 63 \cdot 3 \quad 6 \mathrm{I} \cdot \mathrm{I}\end{array}$ & 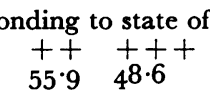 & $\underset{+}{\operatorname{disc}}+++$ & $7 \cdot 0$ \\
\hline
\end{tabular}

1 Corrected for age

2 Uncorrected for age

Table VI shows the partial correlations between the size of the field, for all four fields, and outflow facility when pressure is held constant. All these partial correlations are small and none is statistically significant; $P>O \cdot I$ in each case. This shows that the estimate of average outflow facilityő provides no information as to loss of field that is not given by an estimate of average pressure.

Table VI Partial correlations between size of field and outflow facility when pressure is held constant

\begin{tabular}{|c|c|c|c|c|}
\hline \multirow{2}{*}{ Variable } & \multicolumn{4}{|l|}{ Field } \\
\hline & $\begin{array}{l}\text { Upper } \\
\text { nasal }\end{array}$ & $\begin{array}{l}\text { Lower } \\
\text { nasal }\end{array}$ & $\begin{array}{l}\text { Upper } \\
\text { temporal }\end{array}$ & $\begin{array}{l}\text { Lower } \\
\text { temporal }\end{array}$ \\
\hline Outflow facility & $0 \cdot 22$ & 0.22 & -0.07 & $0 \cdot 04$ \\
\hline
\end{tabular}

